\title{
Crack Resistance and Mechanical Properties of Polyvinyl Alcohol Fiber-Reinforced Cement-Stabilized Macadam Base
}

\author{
Yi Zhao $\mathbb{D}^{1},{ }^{1}$ Xuan Yang, ${ }^{2}$ Qingyu Zhang, ${ }^{2,3}$ Naixing Liang, ${ }^{2}$ Yangkai Xiang, ${ }^{1}$ and Min Qin ${ }^{4}$ \\ ${ }^{1}$ Mountain Bridge and Materials Engineering Research Center of Ministry of Education, School of Materials \\ Science and Engineering, Chongqing Jiaotong University, No. 66 Xuefu Road, Chongqing 400074, China \\ ${ }^{2}$ School of Civil Engineering, Chongqing Jiaotong University, No. 66 Xuefu Road, Chongqing 400074, China \\ ${ }^{3}$ Hebei Jiaotong Vocational \& Technical College, No. 219 Zhujiang Road, Shijiazhuang 050091, China \\ ${ }^{4}$ School of Economics and Management, Chongqing Jiaotong University, No. 66 Xuefu Road, Chongqing 400074, China \\ Correspondence should be addressed to Yi Zhao; 1585513635@qq.com
}

Received 7 November 2019; Revised 11 June 2020; Accepted 16 June 2020; Published 10 July 2020

Academic Editor: Hugo C. Biscaia

Copyright ( $) 2020$ Yi Zhao et al. This is an open access article distributed under the Creative Commons Attribution License, which permits unrestricted use, distribution, and reproduction in any medium, provided the original work is properly cited.

\begin{abstract}
A series of tests were carried out to evaluate crack resistance and mechanical properties of polyvinyl alcohol fiber-reinforced cement-stabilized macadam, which is widely used as pavement base or subbase composite material. Three series of cementstabilized macadam mixtures with cement content of 3.2\%, 3.6\%, and 4.0\% were prepared by incorporating four various contents $\left(0,0.6,0.9\right.$, and $\left.1.2 \mathrm{~kg} / \mathrm{m}^{3}\right)$ and lengths $(12,18,24$, and $30 \mathrm{~mm})$ of polyvinyl alcohol fiber. The optimum polyvinyl alcohol fiber content, fiber length, and cement content were determined based on the mechanical properties of cement-stabilized macadam mixtures. Then, unconfined compressive strength test, compressive resilience modulus test, splitting strength test, flexural tensile strength test, drying shrinkage test, and temperature shrinkage test were carried out in this study. The results show that polyvinyl alcohol fiber-reinforced cement-stabilized prepared by optimum proportions (cement $3.6 \%$, fiber content $0.9 \mathrm{~kg} / \mathrm{m}^{3}$, and fiber length $24 \mathrm{~mm}$ ) has good crack resistance. The incorporation of polyvinyl alcohol fiber can effectively improve compressive strength and splitting strength, while its effect on CRM of cement-stabilized macadam is not remarkable. The anti-dry-shrinkage property and anti-temperature-shrinkage property of the specimens are also drastically improved due to the reinforcement effect of polyvinyl alcohol fiber. Moreover, the crack resistance index is proposed to evaluate the crack resistance of materials. The crack resistance of PVA fiber-reinforced cement-stabilized macadam prepared by optimum proportions is improved by $44.4 \%$. Consequently, the mechanical properties and crack resistance of cement-stabilized macadam are obviously improved by adding polyvinyl alcohol fiber.
\end{abstract}

\section{Introduction}

Cement-stabilized macadam (CSM) is a kind of material stabilized with inorganic binders and exhibits many advantages (such as strong integrity, high strength, strong antiscouring ability, excellent frost resistance, and low cost) and is widely applied in base or subbase of the highway [1-3]. CSM is made of cement, sand, and graded macadam mixed with water. With the interlock of aggregate and the intensity property of cement itself, CSM effectively improves the loadbearing capacity of pavement $[4,5]$. Due to the characteristics of drying shrinkage and temperature shrinkage, there always appear cracks or even plate fracture and broken body in CSM base [6]. Then, the cracks extend to the top layer of pavement, which would lead to the cracking and damage of asphalt pavement, the main cause of early damage to the road $[7,8]$. Therefore, improving the crack resistance and mechanical properties of CSM base is a subject worthy of study.

There are many prevention measures for the cracks of CSM base, for example, optimizing the gradation of aggregate [9], controlling cement dosage [10], improving the quality of construction [11], strengthening early-age curing condition [7], adding modifiers [12], and paving geotextile cloth $[13,14]$. Although these measures have a positive effect on improving the crack resistance of CSM base, reflective cracking of pavement is still serious. Adding a new fiber is a 
simple and efficient way to improve the cracking resistance and mechanical performance of CSM.

At present, fibers, which are widely used as base materials and surface materials in road engineering, include polyester [15], basalt [1], polypropylene [16], polyacrylonitrile [17], lignin [18], and metallic [19]. Lots of researches have shown that fibers can significantly improve mechanical performance and cracking resistance of material stabilized with inorganic binders. Li et al. [20] studied the crack resistance of CSM reinforced with polypropylene fiber. The results indicated that the addition of polypropylene fiber could enhance dry shrinkage crack resistance and thermal shrinkage crack resistance. Liu et al. [21] studied the impact of fiber diameter on the performances of CSM. The results indicated that, with increasing fiber diameter, the average dry shrinkage coefficient of polyester-reinforced CSM first increased and then decreased, while the temperature shrinkage coefficients increased. Simultaneously, the dispersal uniformity of fiber as a technical problem needed to be solved, which had attracted great attention all along [22, 23].

Polyvinyl alcohol (PVA) fiber is a synthetic, semicrystalline, biodegradable, and water-soluble polymer [24, 25]. As a new ecological and environmental road material, PVA is characterized by its advantages of high strength, high elastic modulus, high cement affinity, strong alkali and weather resistance, good durability, green environmental protection, and lower price, so it is applied widely in road engineering field [26]. PVA fiber-reinforced cementitious composite is first developed and produced, which is a new cement-based composite material with high toughness, narrow cracks, and self-healing ability [27]. At the same time, the study on pavement base material of multiscale fiber-reinforced cement-based materials is also reported [28, 29].

It should be noted that most of the investigations, as mentioned earlier, involve the influence of PVA fiber and others on mechanical performances and pavement performance of CSM and cement concrete. However, the reinforcement effect of PVA fiber on CSM material is rarely reported, especially the improvement effects on crack resistance and mechanical properties. The main objective of this study is to reveal the improvement effect of PVA on the mechanical performances and crack resistance of CSM material. To achieve this goal, mixing proportion design of PVA fiber-reinforced CSM (PFRC) is studied to obtain the maximum dry density and the optimum water content from a heavy compaction experiment. Then three series of CSM mixtures (cement content: 3.2\%, 3.6\%, and 4.0\%) are prepared by incorporating four different contents $(0,0.6,0.9$, and $1.2 \mathrm{~kg} / \mathrm{m}^{3}$ ) of PVA fiber. Meanwhile, the effect of fiber length on the mechanical performances and crack resistance of CSM was studied firstly; the four different lengths of fibers $(12,18,24$, and $30 \mathrm{~mm})$ were selected as test materials.

\section{Materials and Experimental Methods}

\subsection{Raw Materials}

2.1.1. Cement. The composite Portland cement used in experimental work is supplied by Xuzhou Zhonglian
Cement Co., Ltd.; its strength grade is 32.5. The performance test results, the technical requirements, and testing methods are shown in Table 1.

2.1.2. Aggregate. Aggregate is crushed limestone $(0-31.5 \mathrm{~mm})$ from Wazikou stone material factory in Xiaoxian County of Anhui Province. All aggregates are divided into five sizes according to particle size. The basic physical performances of aggregate meet the requirements of the relevant criteria, as shown in Table 2. The gradation of aggregate is displayed in Table 3.

2.1.3. PVA Fiber. PVA fiber used in this study is supplied by Anhui Wanwei Group Co., Ltd., and it is a kind of synthetic fiber made from polyvinyl alcohol by special technology. PVA fiber is shown in Figure 1. The physical properties of PVA fiber are shown in Table 4.

PVA fiber dispersion equipment is shown in Figure 2. The clustering of PVA fiber includes three types: monofilament, bundle, and reticulation, as shown in Figure 3. The correlation researches indicate that the uniform 3-dimensional net structures of the interlaced distribution fibers can help to improve the performance of the mixtures [34]. So the ideal cluster condition of fiber is monofilamentous.

2.2. Mixture Proportions Design. In order to determine the maximum dry density and the optimum water content of PFRC, heavy compaction experiment was performed according to Chinese Standard [35]. In order to reveal the influence of PVA fiber on the mechanical performance of CSM, three series (total 39 groups) of PFRC were designed in this experiment.

2.3. Sample Preparation. To ensure uniform distribution of PVA fiber in the mix, aggregate and fiber are mixed for 5 minutes firstly; then cement and water are added and continued to be mixed for 30 minutes. The rotational speed of the stirring shaft is $48(\mathrm{r} / \mathrm{min})$. The mixing quality of CSM mixture is shown in Figure 4.

The prepared mixture is put into a test mold to vibrate, and then the surface of the specimen is flatted. Mold is removed after $48 \mathrm{~h}$ maintenance, and then specimens are cured in the standard curing environment with temperature of $20 \pm 2^{\circ} \mathrm{C}$ and relative humidity of $95 \%$.

\subsection{Experimental Methods}

2.4.1. Heavy Compaction Test. Chinese TJR-III multifunction electric compaction apparatus was employed in heavy compaction test [35]. The mass of driving hammer is $4.5 \mathrm{~kg}$, and drop height is $45 \mathrm{~cm}$, with $98 \times 3$ times hammering for each proportion. The volume of compacting cylinder is $2177 \mathrm{~cm}^{3}$. Permissible maximum nominal particle size is $37.5 \mathrm{~mm}$.

To study the influence of different contents of cement and fiber on the compaction curves of CSM, six different test mixture proportions were designed in this study. PVA is nonmetallic fiber, and when the fraction is too large, it easily agglomerates. Therefore, three series of CSM mixtures (cement content: $3.2 \%$, 
TABle 1: Performance index of composite Portland cement.

\begin{tabular}{|c|c|c|c|c|c|c|c|}
\hline \multirow[t]{2}{*}{ Item } & \multirow[t]{2}{*}{ Fineness (\%) } & \multicolumn{2}{|c|}{$\begin{array}{l}\text { Setting time } \\
\quad(\min )\end{array}$} & \multicolumn{2}{|c|}{$\begin{array}{l}\text { Compressive } \\
\text { strength } \\
(\mathrm{MPa})\end{array}$} & \multicolumn{2}{|c|}{$\begin{array}{c}\text { Bending } \\
\text { strength } \\
(\mathrm{MPa})\end{array}$} \\
\hline & & Initial & Final & $3 \mathrm{~d}$ & $28 \mathrm{~d}$ & $3 \mathrm{~d}$ & $28 \mathrm{~d}$ \\
\hline Test values & 3.6 & 381 & 505 & 17.1 & 38.7 & 4.3 & 8.5 \\
\hline Technical requirements & $\leq 10$ & $>180$ & $<600$ & $\geq 11$ & $\geq 32.5$ & $\geq 2.5$ & $\geq 5.5$ \\
\hline Testing methods [30] & Negative pressure screen method & Vicat apparatus method & \multicolumn{5}{|c|}{$\begin{array}{l}\text { Method of testing cements for } \\
\text { determination of strength (ISO method) }\end{array}$} \\
\hline
\end{tabular}

TABLE 2: Physical performances of aggregate [31].

\begin{tabular}{|c|c|c|c|c|c|}
\hline \multirow{2}{*}{ Item } & \multicolumn{5}{|c|}{ Aggregate size (mm) } \\
\hline & $19-31.5$ & $9.5-19$ & $4.75-9.5$ & $2.36-4.75$ & $0-2.36$ \\
\hline Elongated and flaky particle content (\%) & 7.6 & 8.8 & 7.3 & - & - \\
\hline Gross bulk density $\left(\mathrm{g} / \mathrm{cm}^{3}\right)$ & 2.712 & 2.708 & 2.695 & 2.687 & 2.678 \\
\hline Contents of clay $(\%)$ & 0.8 & 0.8 & 2.3 & 1.7 & 15.3 \\
\hline Crush value $(\%)$ & - & 21.5 & - & - & - \\
\hline Sand equivalent (\%) & - & - & - & - & 62 \\
\hline Plasticity index & - & - & - & - & 3 \\
\hline The mixture ratio (\%) & 16 & 35 & 22 & 4 & 23 \\
\hline
\end{tabular}

TABLE 3: Gradation of aggregate [32].

\begin{tabular}{|c|c|c|c|c|c|c|c|c|}
\hline Sieve size $(\mathrm{mm})$ & 31.5 & 26.5 & 19 & 9.5 & 4.75 & 2.36 & 0.6 & 0.075 \\
\hline Percentage passing & 100 & 93.6 & 75.8 & 46.3 & 27.2 & 19.7 & 10.5 & 3.5 \\
\hline Gradation range (\%) & 100 & $98-93$ & $86-68$ & $58-38$ & $32-22$ & $28-16$ & $15-8$ & $3.5-0$ \\
\hline
\end{tabular}

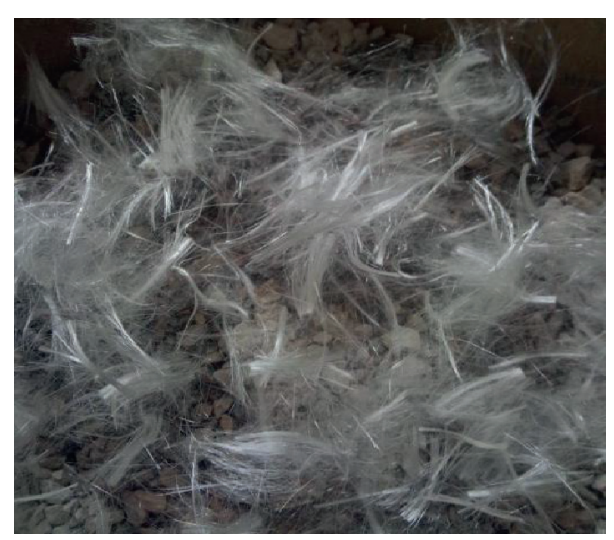

Figure 1: PVA fiber.

TABle 4: Physical properties of PVA fiber [33].

\begin{tabular}{|c|c|c|c|c|c|c|c|c|}
\hline Item & Colour & $\begin{array}{l}\text { Length } \\
(\mathrm{mm})\end{array}$ & $\begin{array}{l}\text { Diameter } \\
(\mu \mathrm{m})\end{array}$ & $\begin{array}{l}\text { Specific } \\
\text { gravity } \\
\left(\mathrm{g} / \mathrm{cm}^{3}\right)\end{array}$ & $\begin{array}{c}\text { Elongation at } \\
\text { break (\%) }\end{array}$ & $\begin{array}{c}\text { Tensile } \\
\text { strength } \\
(\mathrm{MPa})\end{array}$ & $\begin{array}{c}\text { Young's } \\
\text { modulus (GPa) }\end{array}$ & $\begin{array}{c}\text { Decrement of hot } \\
\text { water }\left(90^{\circ} \mathrm{C}, 1 \mathrm{~h}\right)(\%)\end{array}$ \\
\hline $\begin{array}{l}\text { Parameter } \\
\text { values }\end{array}$ & $\begin{array}{l}\text { Silvery } \\
\text { white }\end{array}$ & $\begin{array}{l}12,18 \\
24,30\end{array}$ & 15 & $2.0 \pm 0.25$ & $\leq 7.5$ & $\geq 1533$ & $\geq 35$ & $\leq 2.0$ \\
\hline
\end{tabular}

$3.6 \%$, and $4.0 \%)$ were prepared by incorporating two different contents $\left(0\right.$ and $\left.1.2 \mathrm{~kg} / \mathrm{m}^{3}\right)$ of PVA fiber, and the length of fiber is $30 \mathrm{~mm}$. Five samples for each test mixture proportion were fabricated with different moisture content. Afterwards, the mixtures were sealed with double PVC plastic bags for four hours. Thus, the curve of moisture content versus dry density was made and optimum moisture content and maximum dry density were determined by parallel experiments. 


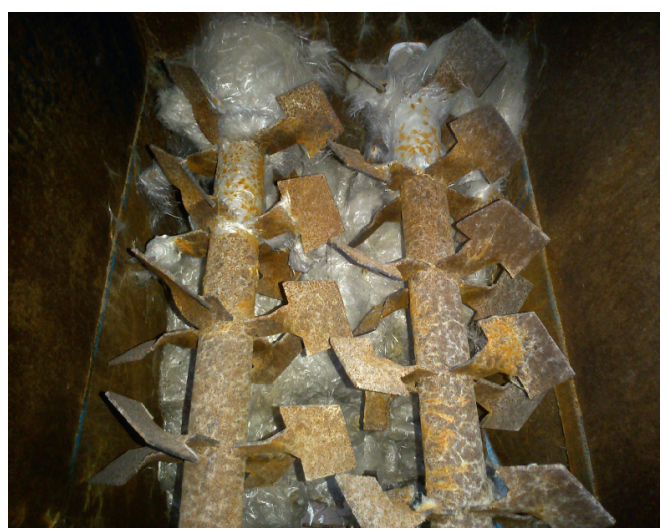

FIgURE 2: Stirring shaft of PVA fiber disperser.

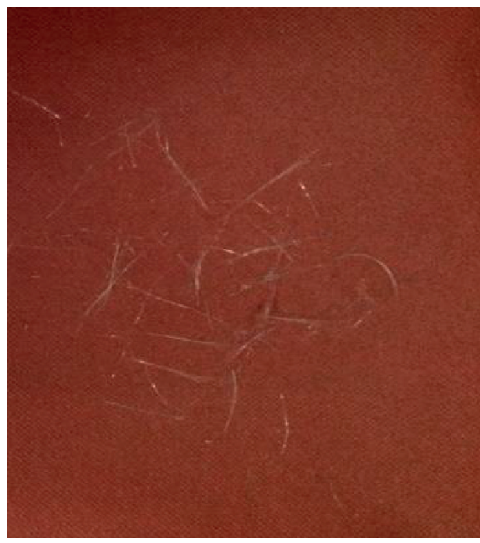

(a)

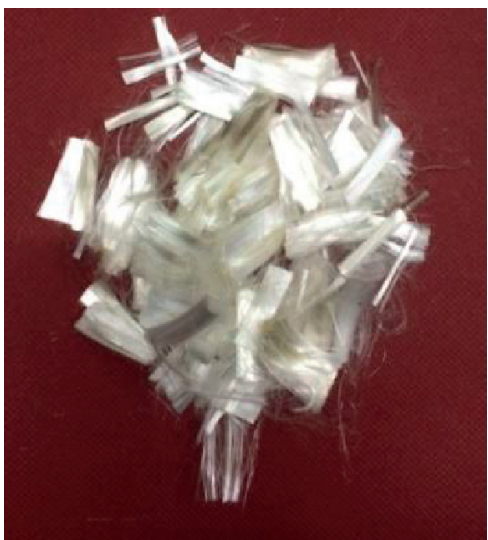

(b)

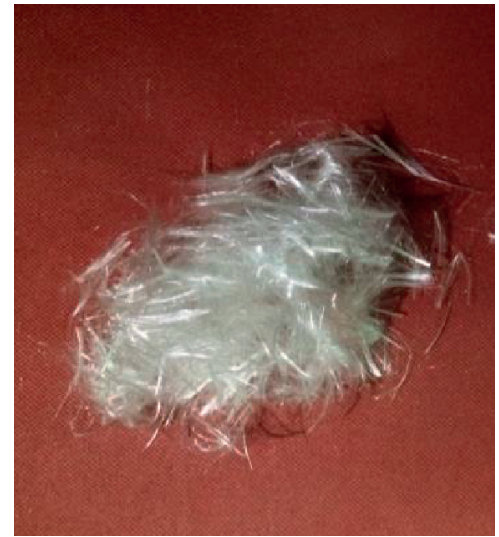

(c)

FIGURE 3: PVA fiber clustering: (a) monofilament, (b) bundle, and (c) reticulation.

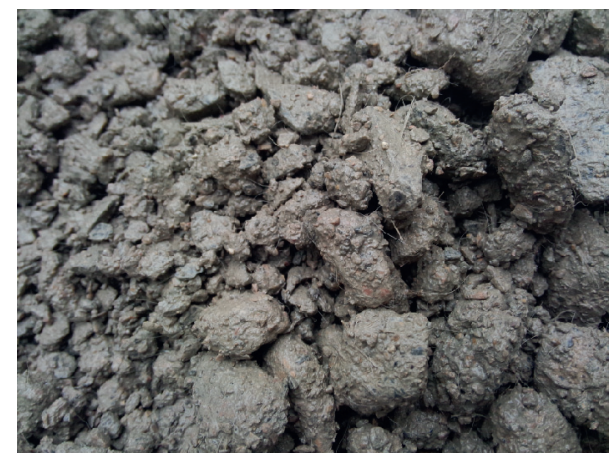

FIgURE 4: The mixing quality of CSM mixture.

2.4.2. Unconfined Compressive Strength (UCS) Test. In the specimens fabricating stage, nearly $6279 \mathrm{~g}$ of raw materials was mixed and blended according to the compaction parameters determined by compaction tests. Then $150 \mathrm{~mm} \times 150 \mathrm{~mm}$ cylindrical specimens were fabricated by pressing forming method. Before UCS test, the specimens were stored in a curing chamber that maintained the temperature of $20 \pm 2^{\circ} \mathrm{C}$ and relative humidity of $95 \%$ for 7 , 28 , and 90 days, respectively. On the last day, the specimens were immersed in water with a temperature of $20 \pm 2^{\circ} \mathrm{C}$. UCS test was carried out after standard curing $[35,36]$, and the loading rate is $1 \mathrm{~mm} / \mathrm{min}$. The laboratory temperature is maintained at $20 \pm 5^{\circ} \mathrm{C}$, and the relative humidity should be $50-70 \%$. The conditions are the same in other mechanical experiments in this paper. Each mixing proportion was conducted on 13 cylindrical specimens, and then the average within the error range was recorded.

2.4.3. Compressive Resilience Modulus (CRM) Test. In this test, the preparation method and curing conditions of specimens are the same as those of UCS test [35]. The curing age is 90 days. Two ends of cylindrical specimens are completely smoothed with cement paste. Fifteen specimens of each mixing proportion were placed for more than 8 hours after leveling and immersed in water for $24 \mathrm{~h}$. The specific pressure remained between 0.5 and $0.7 \mathrm{MPa}$. In order to make the loading roof contact close with the surface of the specimens, two preloadings were carried out by applying half of the maximum load. Then the maximum load was divided into 5-6 stages. The first-stage load was applied and maintained for 1 minute. The load was unloaded while 
the reading was recorded by micrometer or displacement sensor so that the specimen could fully rebound, and the displacement reading was rerecorded until $30 \mathrm{~s}$. Loading and unloading of the specimens were carried out step by step. The CRM test of PFRC is shown in Figure 5.

2.4.4. Splitting Strength Test. The tensile strength of a composite can be indirectly measured by splitting strength test. This test has become increasingly prevalent as it can be more easily run. Furthermore, the failure pattern observed in this test reflects the tensile properties of materials [37-40]. The splitting strength test was done at loading rate of $1 \mathrm{~mm} / \mathrm{min}$ [35]. The splitting strength test of PFRC is as shown in Figure 6. The splitting strengths of 13 cylindrical specimens (the size of test specimen: $150 \mathrm{~mm} \times 150 \mathrm{~mm}$ ) were tested after standard curing. The layering width is $18.75 \mathrm{~mm}$. When the specimens were destroyed, the maximum pressure was recorded to calculate splitting strength.

2.4.5. Flexural Tensile Strength (FTS) Test. The sketch map of FTS test and test apparatus are shown in Figure 7. The three dividing points loading test was done by a flexural testing machine at a loading rate of $50 \mathrm{~mm} / \mathrm{min}$ [35]. Fifteen beam specimens of $100 \mathrm{~mm} \times 100 \mathrm{~mm} \times 400 \mathrm{~mm}$ with a span of $300 \mathrm{~mm}$ (at the ages of 7, 28, and 90 days) for each mixing proportion were applied to study FTS.

2.4.6. Drying Shrinkage Test (DST). The sketch map of DST and test apparatus are shown in Figure 8. Three small beam specimens with the size of $100 \mathrm{~mm} \times 100 \mathrm{~mm} \times 400 \mathrm{~mm}$ for each mixing proportion are applied to study dry shrinkage property, which were cured in the standard curing room for 7 days. Then vernier calipers were used to measure the initial length of the small beam specimens three times to offer the arithmetic mean as the datum length. The shrinkage measuring apparatus was put into a shrinkage chamber that maintained the temperature of $20 \pm 1^{\circ} \mathrm{C}$ and relative humidity of $60 \pm 5 \%$ together with the specimens.

2.4.7. Temperature Shrinkage Test (TST). The sketch map of TST and test apparatus are shown in Figure 9. The temperature shrinkage coefficient (TSC) of PFRC is studied in the dry state. Three small beam specimens with the size of $100 \mathrm{~mm} \times 100 \mathrm{~mm} \times 400 \mathrm{~mm}$ for each mixing proportion were applied to study temperature shrinkage property, which were cured in the standard curing room for 7,28 , and 90 days, respectively. Then the small beam specimens were dried to a constant weight. The TSTs were done by temp shock at a cooling rate of $0.5^{\circ} \mathrm{C} / \mathrm{min}$ for three hours [34]. The test starts from high temperature and cools down step by step. Four temperature levels were tested, which are 60-50, $50-40,40-30$, and $30-20^{\circ} \mathrm{C}$, respectively. The dial indicator reading was read five minutes before the end of heat preservation.

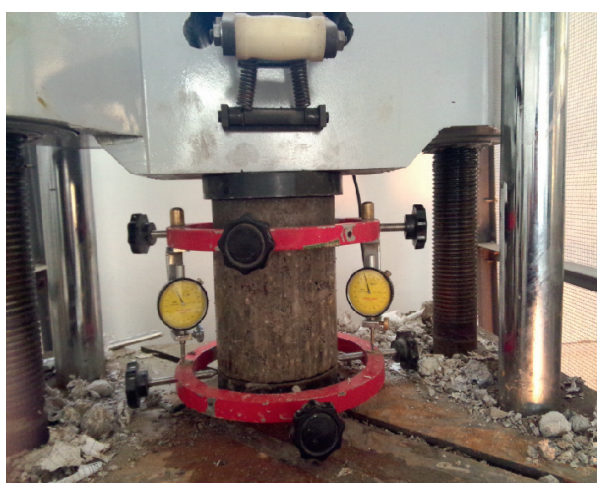

Figure 5: CRM test.

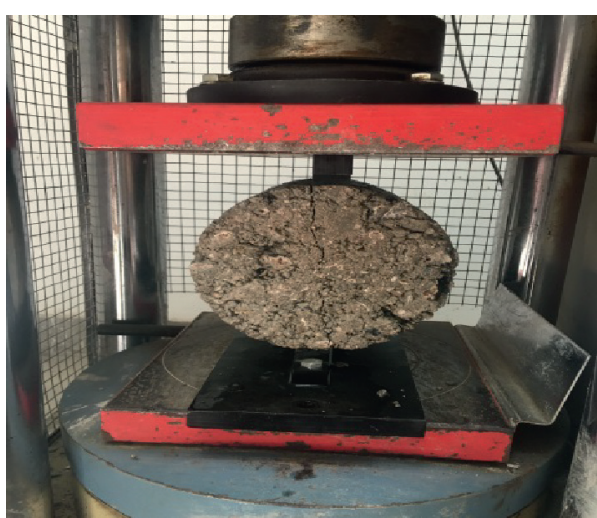

FIGURE 6: Splitting strength test.
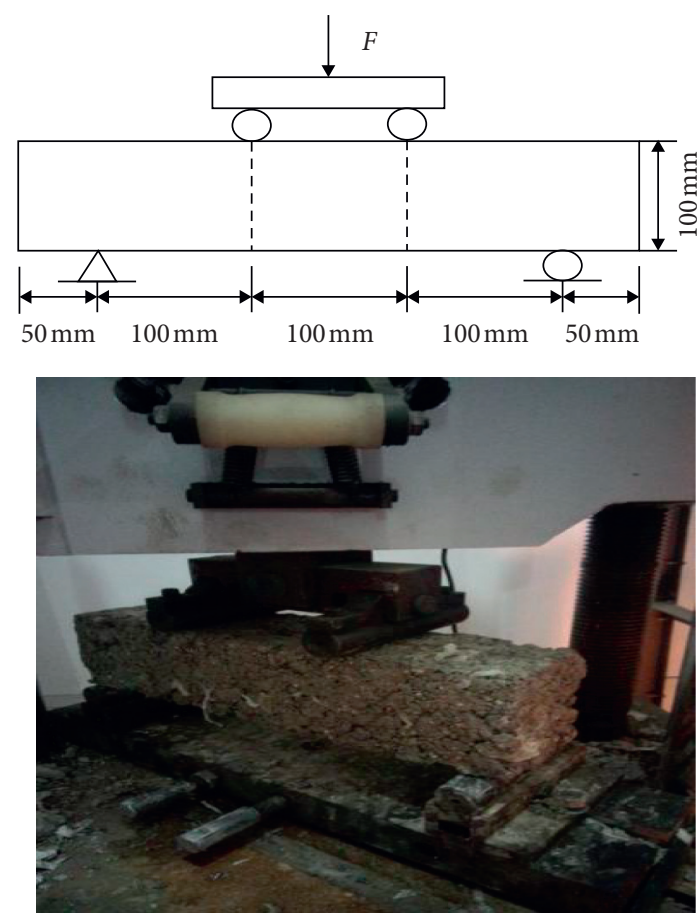

FIgURE 7: Sketch map of flexural-tensile strength test. 

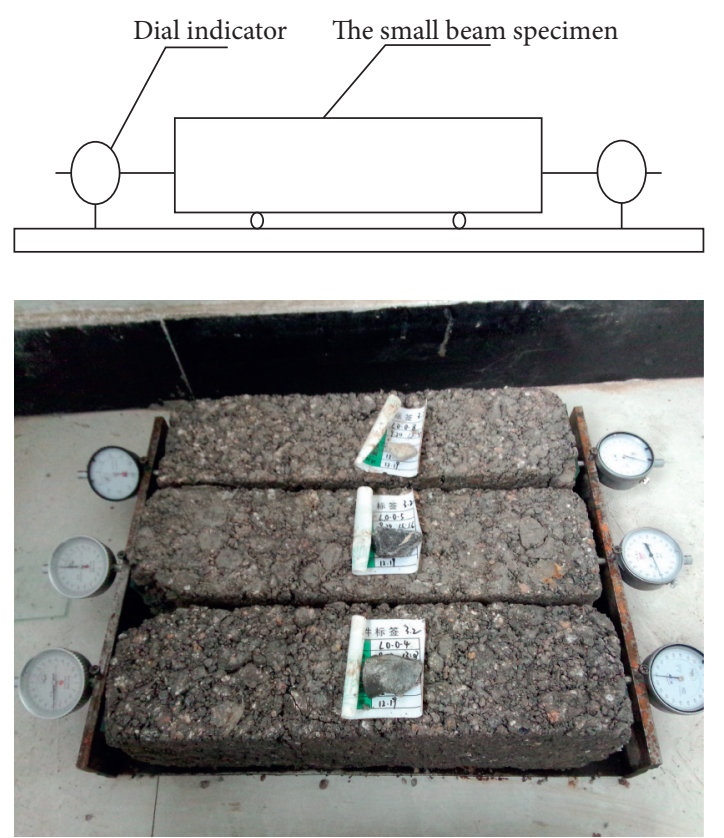

FIGURE 8: Sketch map of drying shrinkage test and test apparatus and test apparatus.

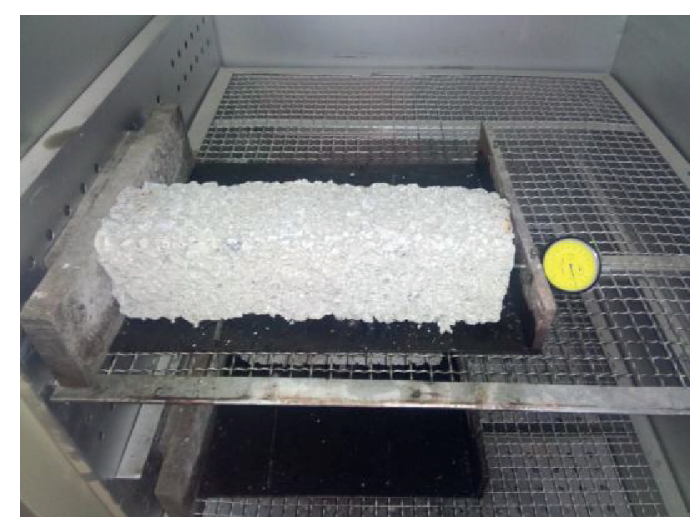

FIGURE 9: Sketch map of TST and test apparatus.

\section{Results and Discussion}

3.1. Heavy Compaction Test Analysis. The results of the heavy compaction test are shown in Table 5. The results show that when the cement content is the same, the optimum moisture content and the maximum dry density of CSM with fiber content of $1.2 \mathrm{~kg} / \mathrm{m}^{3}$ are very close to those of CSM without fiber. The differences in maximum dry density and optimum moisture content are not more than $0.08 \mathrm{~g} / \mathrm{cm}^{3}$ and $0.5 \%$, respectively. So the content of PVA fiber in a certain range may be considered as unaffected for the maximum dry density and the optimum moisture content.

3.2. UCS Analysis. The studies show that the reinforcement effect of fiber on UCS of CSM has a great relationship with fiber content, fiber length, cement content, and curing age
TABLE 5: Maximum dry density and optimum moisture content.

\begin{tabular}{lcccccc}
\hline & \multicolumn{6}{c}{ Fiber content $\left(\mathrm{kg} / \mathrm{m}^{3}\right)$} \\
Item & \multicolumn{5}{c}{0} & \multicolumn{4}{c}{1.2} \\
& 3.2 & 3.6 & 4.0 & 3.2 & 3.6 & 4.0 \\
\hline $\begin{array}{l}\text { Maximum dry density } \\
\text { (g/cm }\end{array}$ & 2.371 & 2.369 & 2.373 & 2.370 & 2.371 & 2.373 \\
$\begin{array}{l}\text { Optimum moisture } \\
\text { content (\%) }\end{array}$ & 5.5 & 5.6 & 5.6 & 5.5 & 5.5 & 5.5 \\
\hline
\end{tabular}

$[1,41]$, and therefore the influence factors of UCS of PFRC are discussed from the above four aspects.

The trend charts of 7-, 28-, and 90-day UCS of CSM with different fiber content and length are shown in Figure 10. In the legend, take 3.2-7 for example; 3.2-7 denotes that cement content is $3.2 \%$, and the curing age is 7 days. The standard deviation of the specimens is $6.3-14.4 \%$, which meets the requirements of standard specification $(<15 \%)$. The addition of PVA fiber in CSM greatly improves the UCS. In general, the addition of fiber results in an increase in the load-carrying capacity of composite samples. This performance boost stems from the existence of the transverse confinement effect between fiber and cement-based material [42]. The trend chart of UCS average growth rate of CSM with different fiber content is shown in Figure 11. Compared with fiber content of $0 \%$, the UCS average growth rates of CSM with fiber content of $0.6,0.9$, and $1.2 \mathrm{~kg} / \mathrm{m}^{3}$ are $19.92 \%$, $19.46 \%$, and $18.63 \%$, respectively, and the UCS average growth rates of CSM with fiber lengths of $12,18,24$, and $30 \mathrm{~mm}$ are $18.91 \%, 19.32 \%, 20.58 \%$, and $19.18 \%$, respectively. As far as UCS is concerned, the optimal PVA fiber content is closely related to fiber length.

In the legend of Figures 12 and 13, take $0.6-7$ for example; $0.6-7$ denotes that fiber content is $0.6 \mathrm{~g} / \mathrm{cm}^{3}$, and the curing age is $7 \mathrm{~d}$.

Figure 12 shows that, with the increase of fiber length, the trend of UCS of CSM increases first and then decreases. Compared with CSM without PVA, the UCS of PFRC with fiber lengths of $12,18,24$, and $30 \mathrm{~mm}$ increases by $15.1 \%, 7.2 \%$, $16.7 \%$, and $11.8 \%$, respectively, on average. As far as UCS is concerned, the optimum length of PVA fiber is $24 \mathrm{~mm}$.

Figure 13 shows that the UCS of PFRC nonlinearly increases with increasing cement content. Compared with cement content of $3.2 \%$, the UCS of PFRC with cement content of $3.6 \%$ and $4.0 \%$ increases by $18.4 \%$ and $35.4 \%$, respectively, on average. It reveals that cement content has a certain influence on PVA fiber enhancement of UCS of CSM base.

From Figure 10, it can be found that the UCS of all series of PFRC increases as the age increases. Compared with 7, 28, and $90 \mathrm{~d}$, UCS of PFRC with cement content of $3.2 \%, 3.6 \%$, and $4.0 \%$ increases by $29.8 \%$ and $52.5 \%, 24.9 \%$ and $45.2 \%$, and $22.5 \%$ and $37.8 \%$, respectively. For $7 \mathrm{~d}$, the UCSs of PFRC with cement content of $3.2 \%, 3.6 \%$, and $4.0 \%$ are about 2.5-3.2 MPa, 3.1-3.8 MPa, and 4.0-4.8 MPa, respectively; all of them can meet the technical specification requirements for heavy traffic on the expressway as subbase material $(>2.5 \mathrm{MPa})$ and base material $(>3.0 \mathrm{MPa})[43]$. 


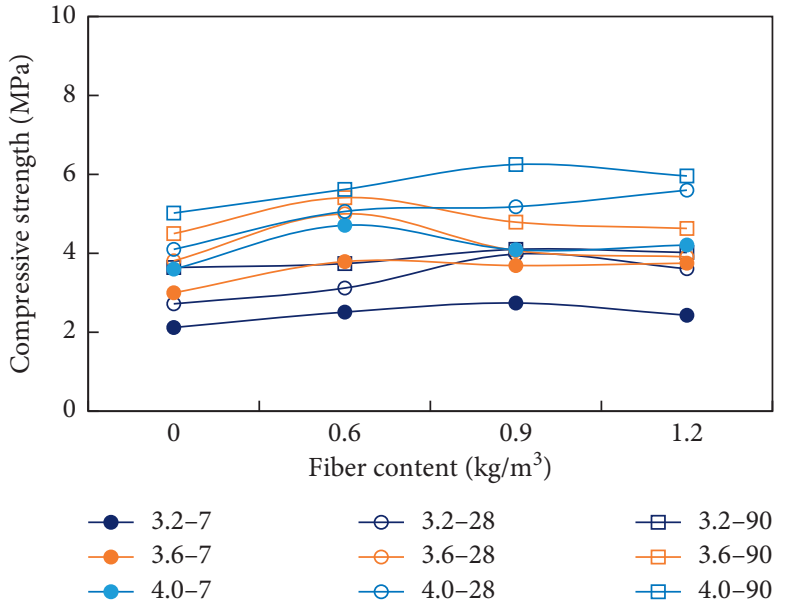

(a)

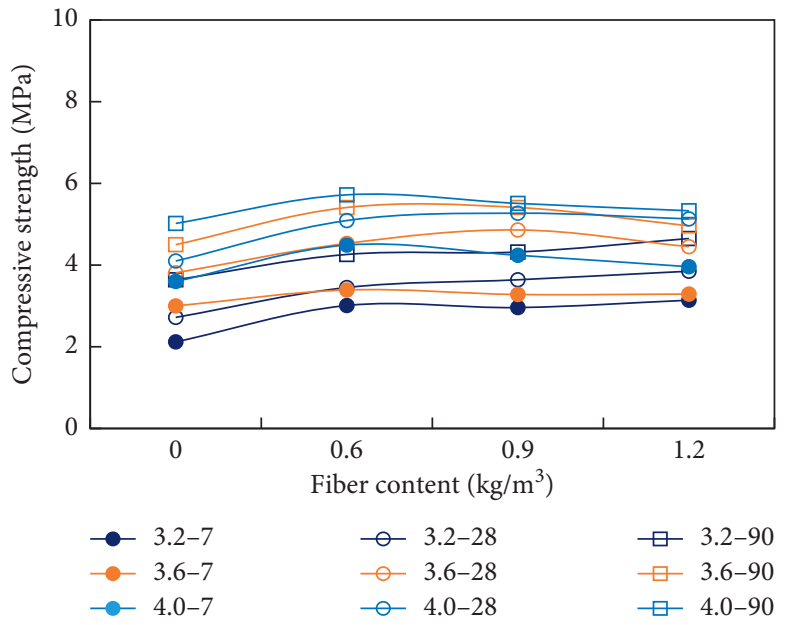

(c)
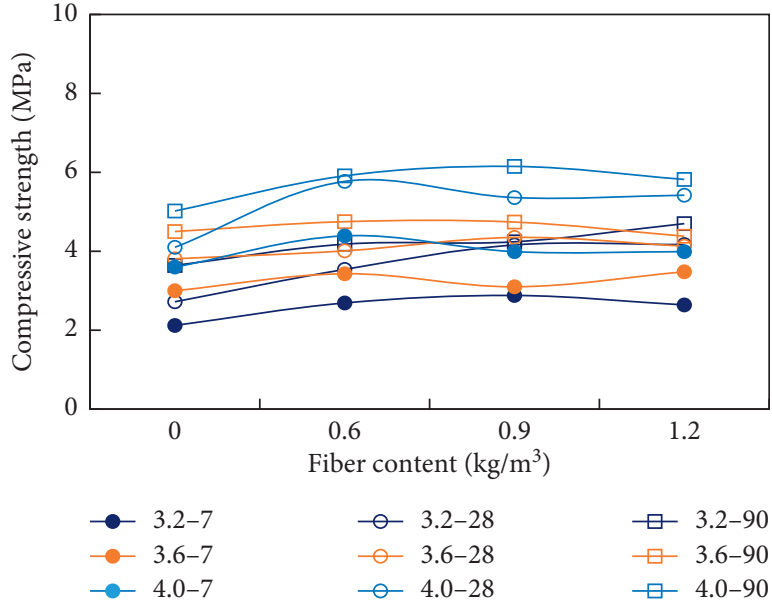

$-3.2-28$

$-3.6-28$

- $3.2-90$

- $4.0-28$

(b)
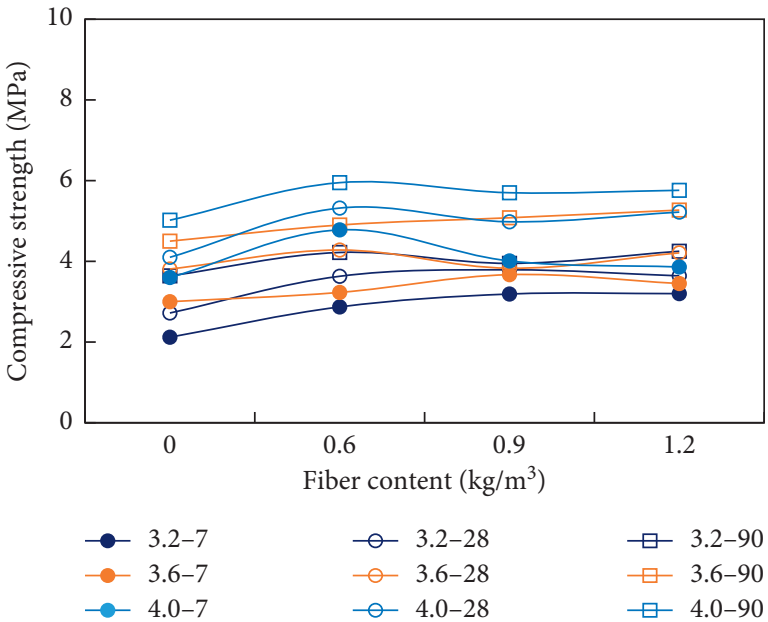

(d)

FIGURE 10: Trend chart of UCS of CSM with different fiber contents: (a) fiber length of $12 \mathrm{~mm}$, (b) fiber length of $18 \mathrm{~mm}$, (c) fiber length of $24 \mathrm{~mm}$, and (d) fiber length of $30 \mathrm{~mm}$.

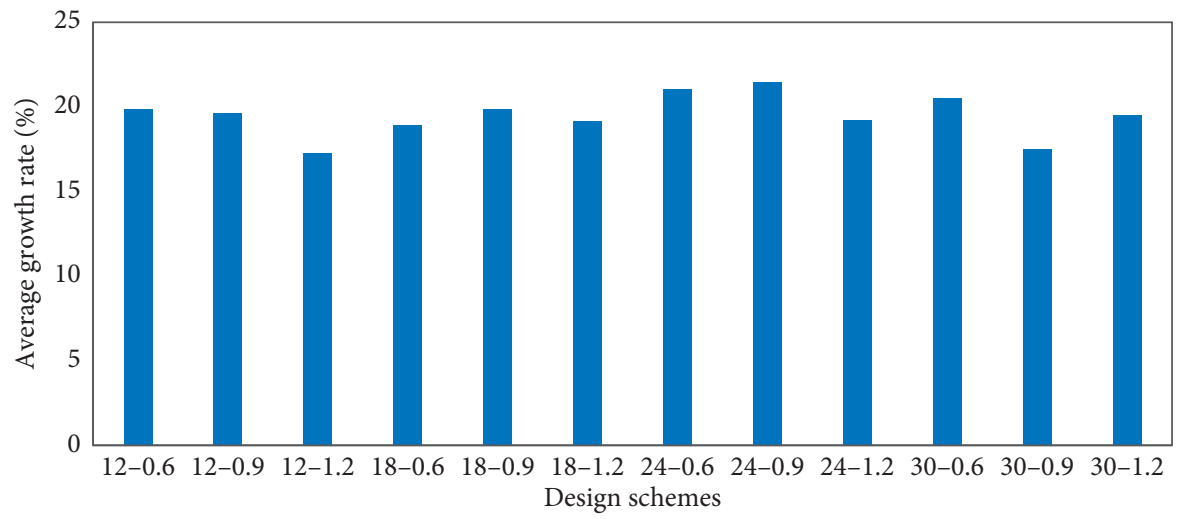

FIGURE 11: Trend chart of UCS average growth rate of CSM with different fiber contents.

3.3. CRM Analysis. The standard deviation of the specimens is $5.7-13.5 \%$, which meets the requirements of standard specification $(<15 \%)$. Figure 14 shows that the CRM of PFRC with different fiber length increases first and then decreases with the increase of fiber content, but the CRM of PFRC with fiber length of $24 \mathrm{~mm}$ irregularly changes. Compared with CSM without fiber, the CRM of PFRC with fiber content of $0.6,0.9$, and $1.2 \mathrm{~kg} / \mathrm{m}^{3}$ averagely 


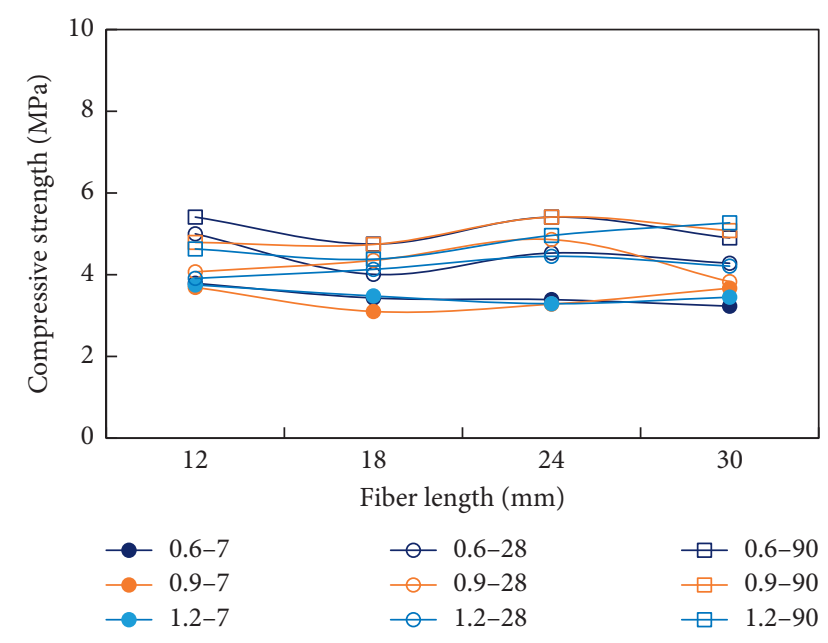

FIGURE 12: Trend chart of UCS of CSM with different fiber lengths.

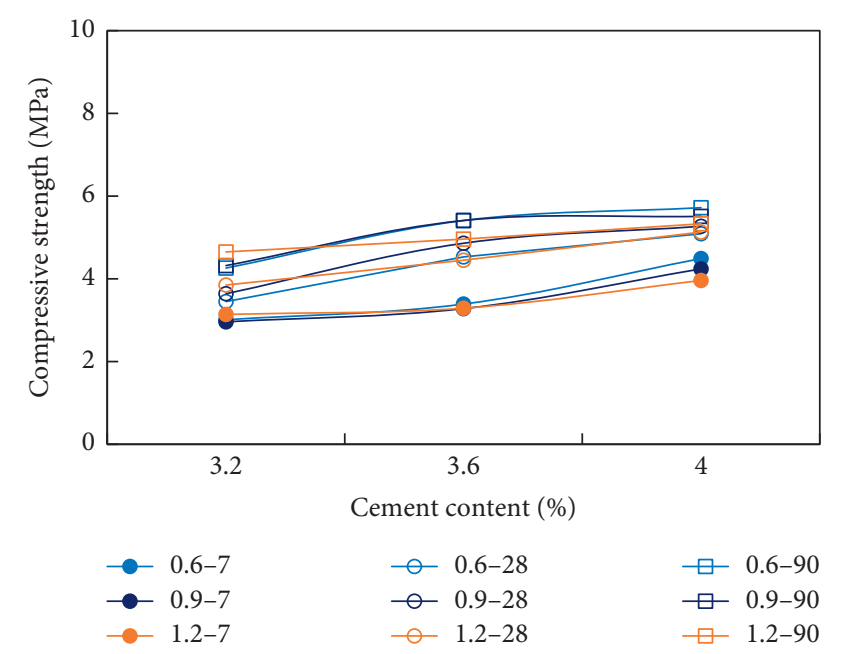

FIgURE 13: Trend chart of UCS of CSM with different cement contents.

increases by $4.64 \%, 3.96 \%$, and $2.08 \%$, respectively. The optimum fiber content corresponding to the CRM of PFRC varies with the fiber length. So the optimum content range of PVA fibers is $0.6-0.9 \mathrm{~kg} / \mathrm{m}^{3}$. In the legend, take $3.2-7$ for example; it denotes that the cement content is $3.2 \%$, and the curing age is $7 \mathrm{~d}$.

Figure 14 shows that when fiber content is constant, the CRM of PFRC with cement content of $3.2 \%$ and $3.6 \%$ increases first and then decreases with the increase of fiber length, but the CRM of PFRC with cement content of $4.0 \%$ irregularly changes. The optimum fiber length corresponding to the CRM of PFRC varies with fiber content. So the optimum length range of PVA fiber is $18-24 \mathrm{~mm}$.

When the fiber lengths are 12 and $30 \mathrm{~mm}$, the CRM of PFRC increases along with the increasing of cement content, but when the fiber lengths are 18 and $24 \mathrm{~mm}$, the CRM of PFRC increases first and then decreases with the increase of cement content. So the optimum cement content of PFRC with fiber lengths of $18 \mathrm{~mm}$ to $24 \mathrm{~mm}$ is $3.6 \%$.
3.4. Splitting Strength Analysis. The relationships between splitting strength of PFRC and fiber content are shown in Figure 15. In the legend, taking $7-3.2$ as an example, it denotes that the curing age is 7 days, and cement content is $3.2 \%$. The standard deviation of the specimens is $4.9-13.8 \%$, which meets the requirements of standard specification $(<15 \%)$. The results show that the splitting strength of PFRC with different fiber length increases first and then decreases with the increase of fiber content. Compared with CSM without PVA, the splitting strength of CSM with fiber content of $0.6,0.9$, and $1.2 \mathrm{~kg} / \mathrm{m}^{3}$ averagely increases by $4.73 \%, 12.50 \%$, and $6.98 \%$, respectively. So the optimum fiber content of PFRC is $0.9 \mathrm{~kg} / \mathrm{m}^{3}$.

Figure 15 shows that the splitting strength of PFRC increases along with the increase of fiber length. The optimum fiber length of PFRC is $18-24 \mathrm{~mm}$. The splitting strength of PFRC increases nonlinearly with the increase of cement content. Compared with cement content of $3.2 \%$, the splitting strength of PFRC with cement content of $3.6 \%$ and $4.0 \%$ after curing age of 28 days averagely increases by $6.82 \%$ and $28.88 \%$, respectively. It implies that cement content is a key effect factor on splitting strength of PFRC. As the cement content increases, the hydrous binding materials increase gradually and the density of the whole composite increases gradually. Besides, the proportion of the interface zone also increases gradually, and then the strength and density of the interface zone increase gradually [44]. For the above reasons, as cement content increases, there is an increasing tendency in the splitting strength of PFRC.

3.5. FTS Analysis. The relationships between FTS of PFRC with fiber content of $0.9 \mathrm{~kg} / \mathrm{m}^{3}$ and fiber length are shown in Figure 16. The legend of Figure 16 has the same meaning as that of Figure 15. The standard deviation of the specimens is $8.2-14.6 \%$, which meets the requirements of standard specification $(<15 \%)$. The results show that the FTS of PFRC increases first and then decreases with the increase of fiber length. So the optimum fiber length of PFRC is $18 \mathrm{~mm}$ to $24 \mathrm{~mm}$. Compared with CSM without PVA, the FTS of PFRC with fiber length of $24 \mathrm{~mm}$ increases by $8.67 \%$.

The relationships between FTS of PFRC with fiber content of $0.9 \mathrm{~kg} / \mathrm{m}^{3}$ and cement content are shown in Figure 16. The results show that the FTS of PFRC increases along with the increasing of cement content. Compared with cement content of $3.2 \%$, the FTS of PFRC with cement content of $3.6 \%$ and $4.0 \%$ after curing age of 28 days averagely increases by $1.18 \%$ and $3.83 \%$, respectively.

3.6. Drying Shrinkage Property Analysis. In the legend of Figure 17, taking $3.2-12$ as an example, it denotes that the curing age is 7 days, and fiber length is $12 \mathrm{~mm}$. The relationships between dry shrinkage coefficient (DSC) of PFRC and curing age are shown in Figure 17(a). The results show that the DSC of PFRC increases with the increment of age, but the speed of the DSC increase is reduced in the later period. The relationships between DSC of PFRC and fiber length are shown in Figure 17(b). The results show that, with the increase of PVA fiber length, the DSC decreases firstly and then increases, and there is optimum fiber length. 


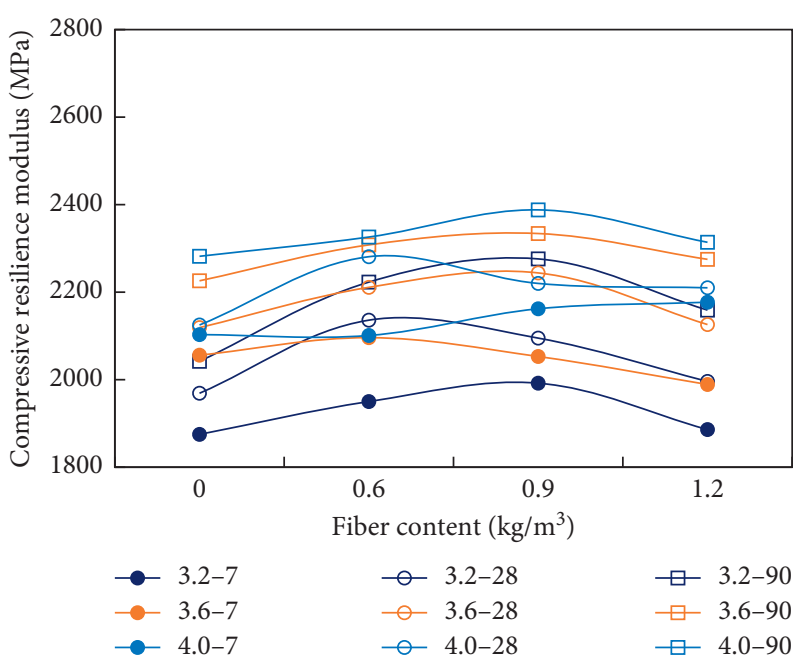

(a)

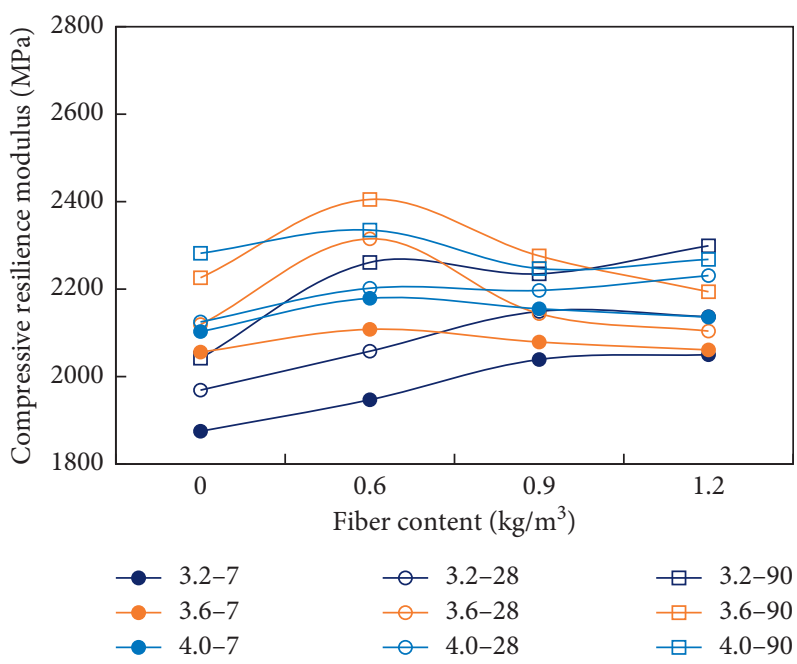

(c)
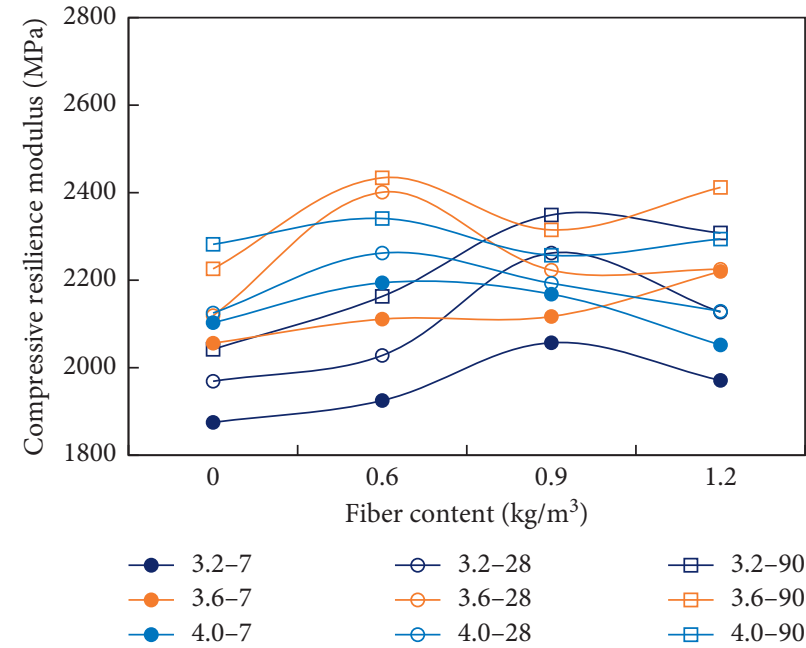

$-3.2-28$
$-3.6-28$
$-4.0-28$

七 $3.2-90$

$\square$ - 3.6-90

$\square \quad 4.0-90$

(b)

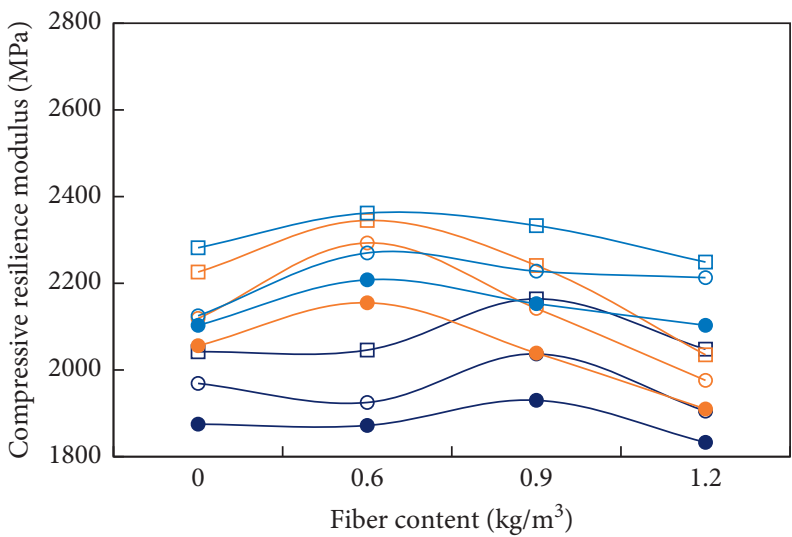

- $3.2-28$

— 3.2-90

$-\bullet 3.2-7$
$-\bullet \quad 3.6-7$
$--4.0-7$

-0 3.6-28

$\square-3.6-90$

○- 4.0-28

- $4.0-90$

(d)

FIGURE 14: Trend chart of CRM of CSM. (a) Fiber length of $12 \mathrm{~mm}$, (b) fiber length of $18 \mathrm{~mm}$, (c) fiber length of $24 \mathrm{~mm}$, and (d) fiber length of $30 \mathrm{~mm}$.
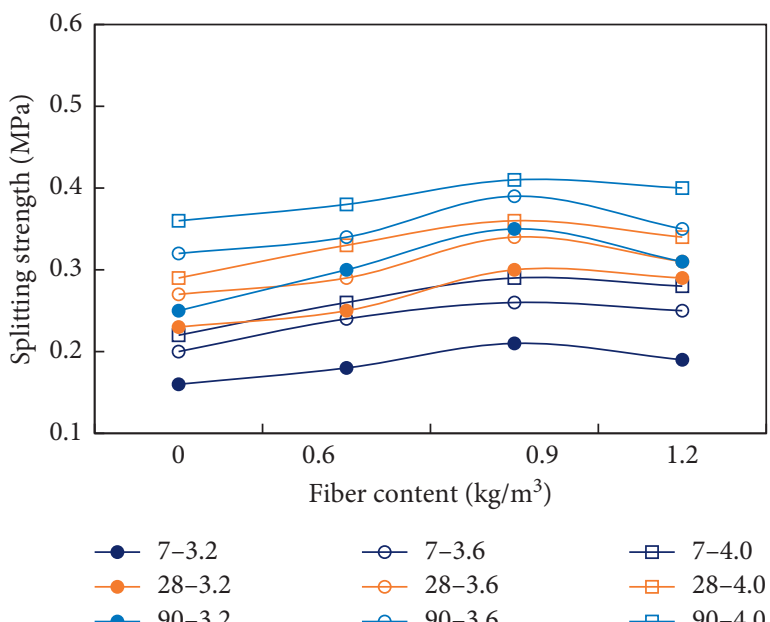

口- 7-4.0

$\square-28-4.0$

- 90-4.0

- 90-3.6

(a)
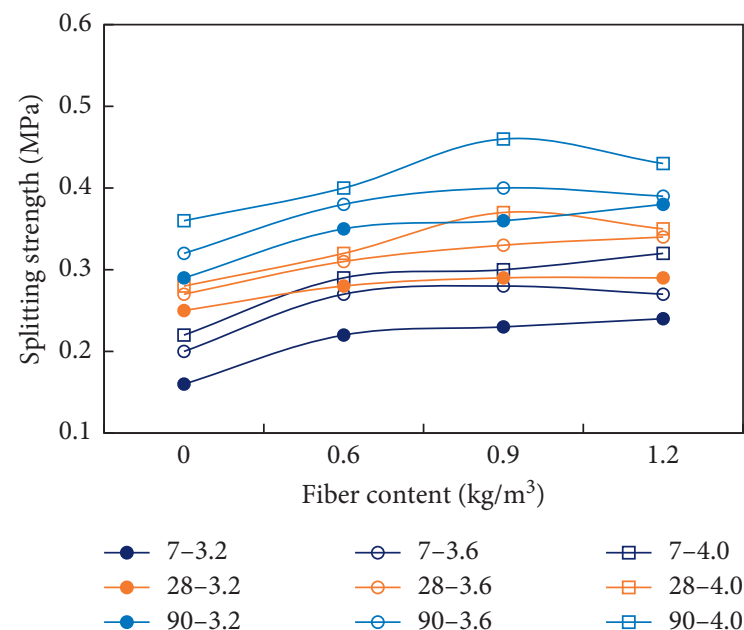

$\begin{array}{ll}- & 7-3.6 \\ - & 28-3.6\end{array}$

Ð 7-4.0

- $90-3.6$

$-90-4.0$

FIGURE 15: Continued. 


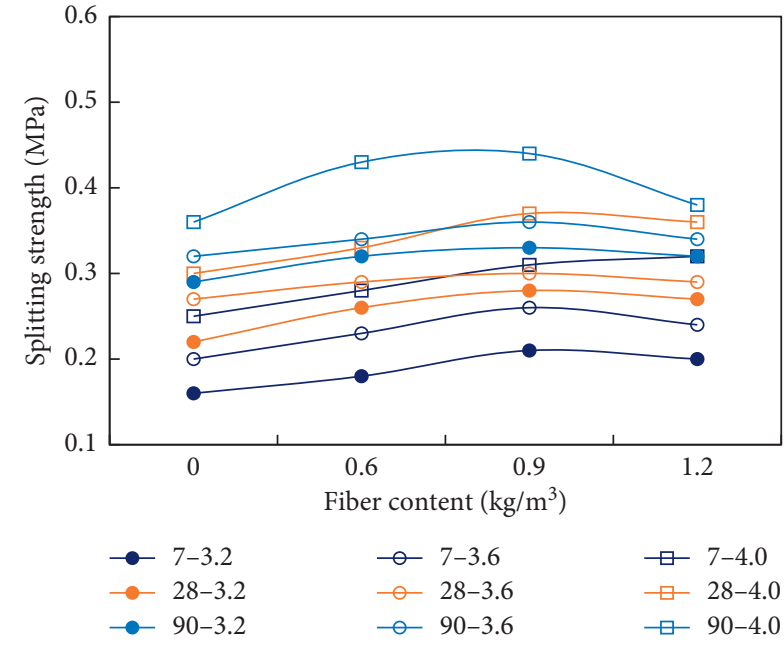

(c)

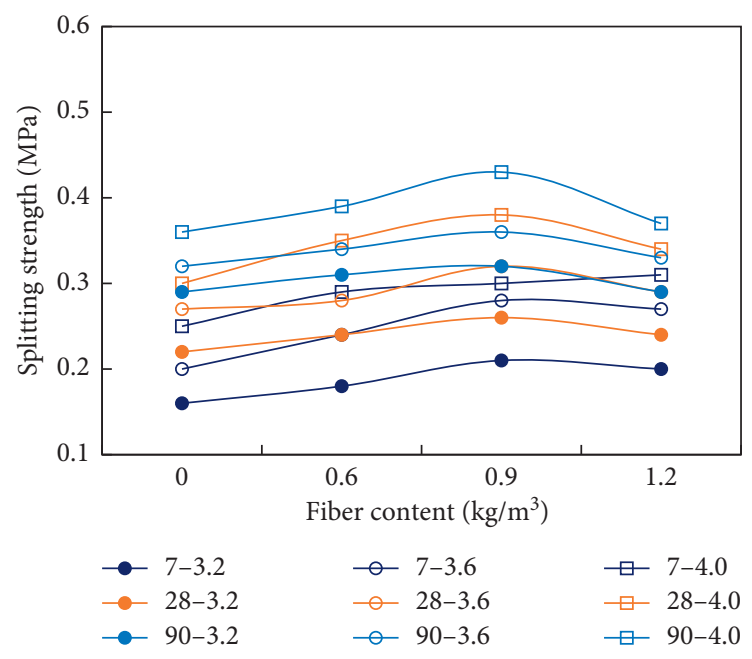

(d)

Figure 15: Trend chart of splitting strength of CSM: (a) fiber length of $12 \mathrm{~mm}$, (b) fiber of length $18 \mathrm{~mm}$, (c) fiber length of $24 \mathrm{~mm}$, and (d) fiber length of $30 \mathrm{~mm}$.

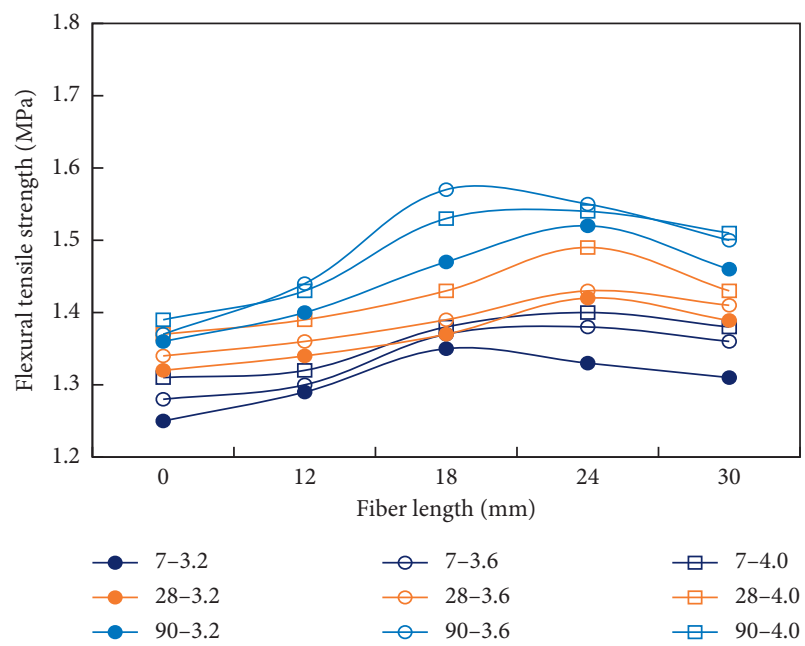

(a)

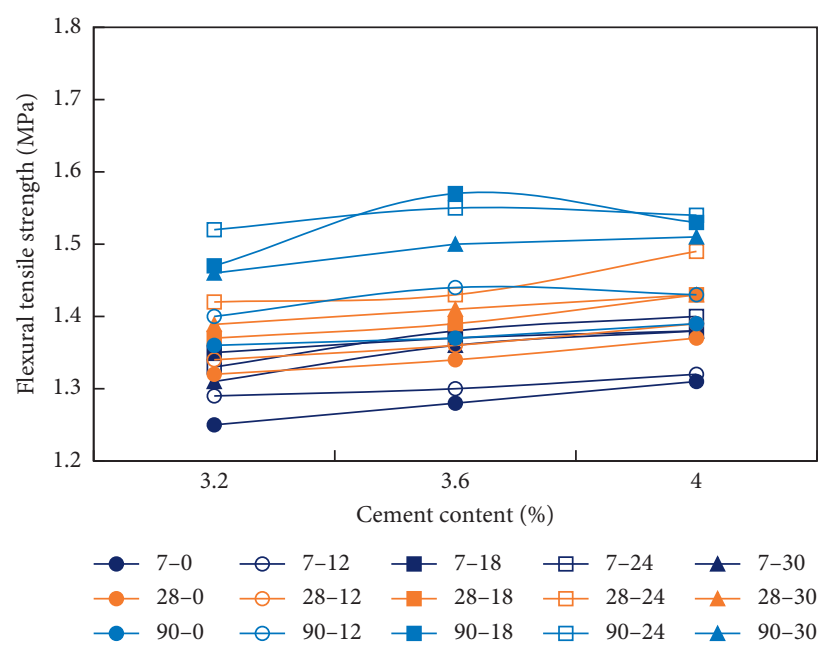

(b)

FIgURE 16: Trend chart of FTS of CSM: (a) fiber length and (b) cement content.

Compared with CSM without PVA, the DSC of PFRC with $12,18,24$, and $30 \mathrm{~mm}$ averagely decreases by $8.38 \%, 15.79 \%$, $22.49 \%$, and $17.96 \%$, respectively. So when the fiber length is $24 \mathrm{~mm}$, the DSC of PFRC is the smallest.

The relationships between the DSC of PFRC and cement content are shown in Figure 17(c). The results show that, with the increase of cement content, the DSC of PFRC increases gradually. Compared with CSM without PVA, the DSC of PFRC with cement content of 3.2\%, 3.6\%, and $4.0 \%$ decreases by $19.8 \%, 15.9 \%$, and $4.6 \%$, respectively.

3.7. Temperature Shrinkage Property Analysis. The trend charts of TSC of PFRC with different temperature levels are shown in Figure 18. The legend of Figure 18 has the same meaning as that of Figure 17. The results show that, with the increase of temperature levels, the TSC of PFRC increases gradually. Compared with temperature levels of $(30-20]^{\circ} \mathrm{C}$, the TSCs of PVA fiber-reinforced CSM in temperature levels of (40-30], (50-40], and $(60-50]^{\circ} \mathrm{C}$ averagely increase by $12.1 \%, 26.9 \%$, and $41.4 \%$ respectively.

Figure 18 shows that, with the increase of curing age, the TSCs of PFRC with different fiber length increasel gradually. Compared with curing age of 7 days, the TSCs of PFRC after curing age of 28 and 90 days averagely increase by $30.7 \%$ and $44.7 \%$, respectively.

The incorporation of PVA can effectively improve the anti-temperature-shrinkage property of CSM. Compared with CSM without PVA, the TSCs of PFRC with fiber lengths of $12,18,24$, and $30 \mathrm{~mm}$ averagely reduce by $9.4 \%, 12.0 \%$, $36.9 \%$, and $11.8 \%$, respectively. So the optimum fiber length is $24 \mathrm{~mm}$. 


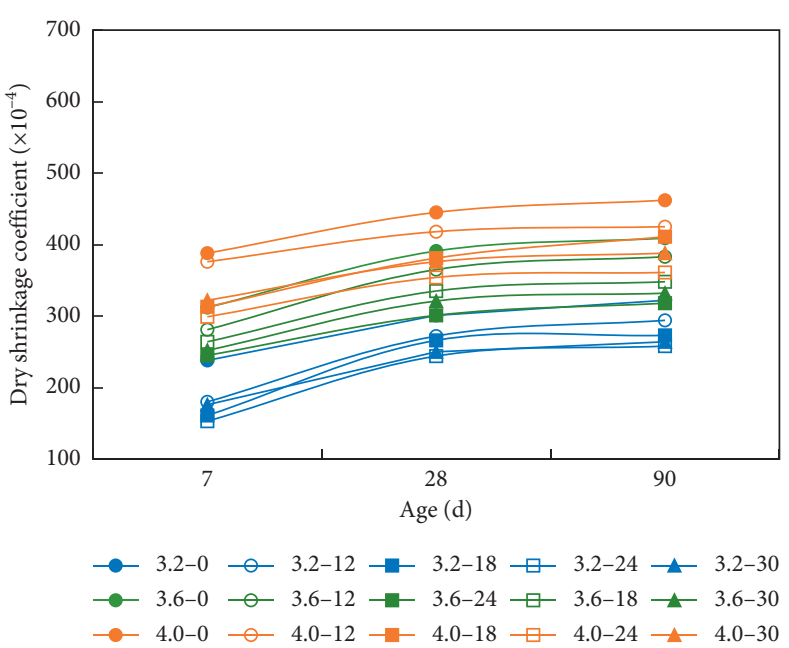

(a)

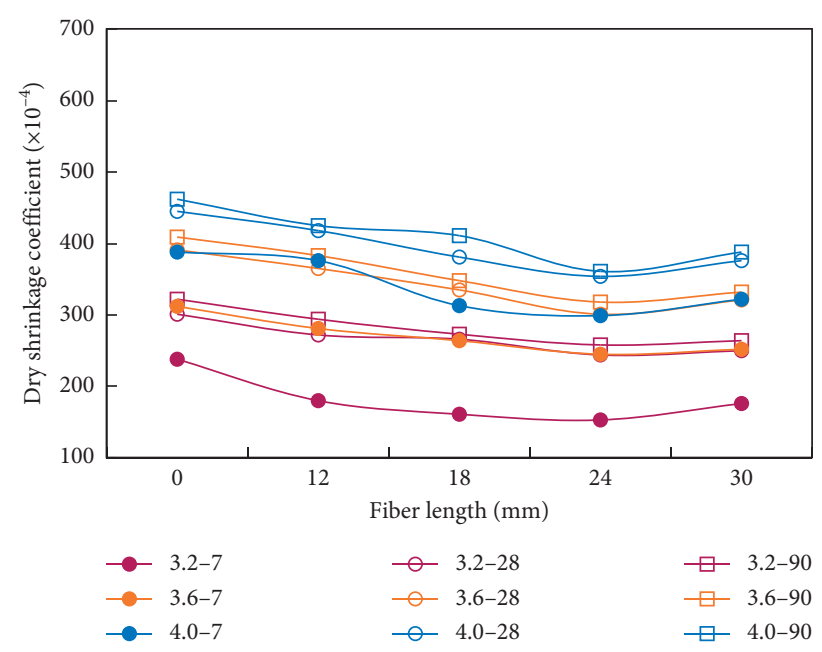

(b)

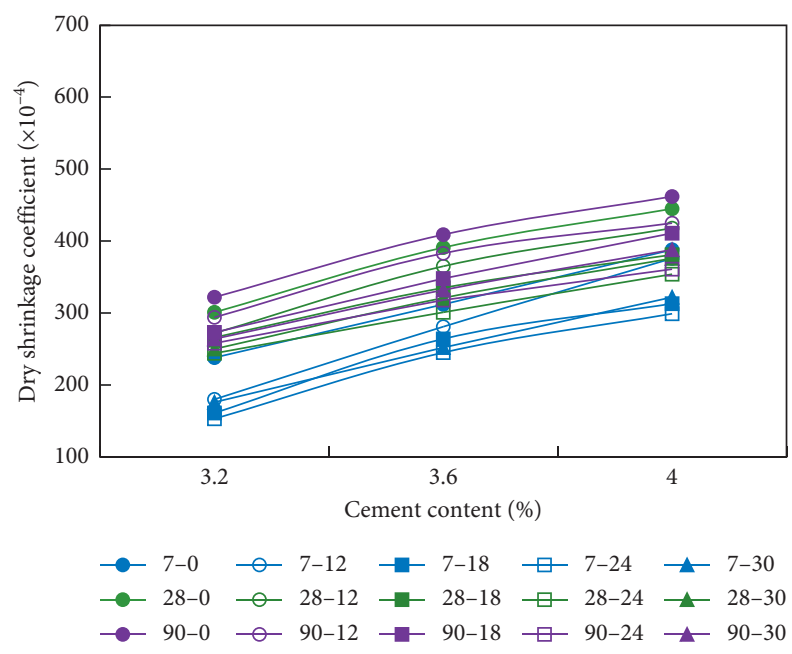

(c)

Figure 17: Trend chart of DSC of PFRC: (a) age, (b) fiber length, and (c) cement content.

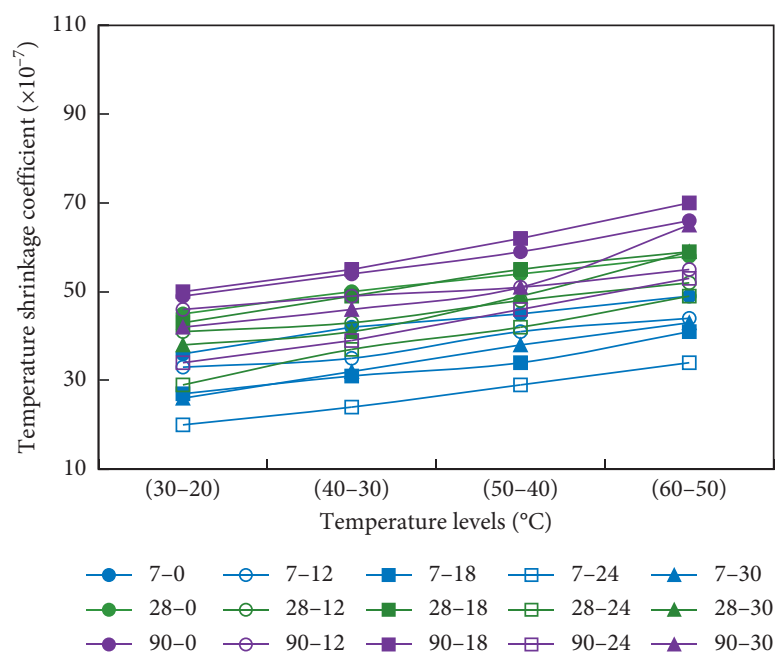

(a)

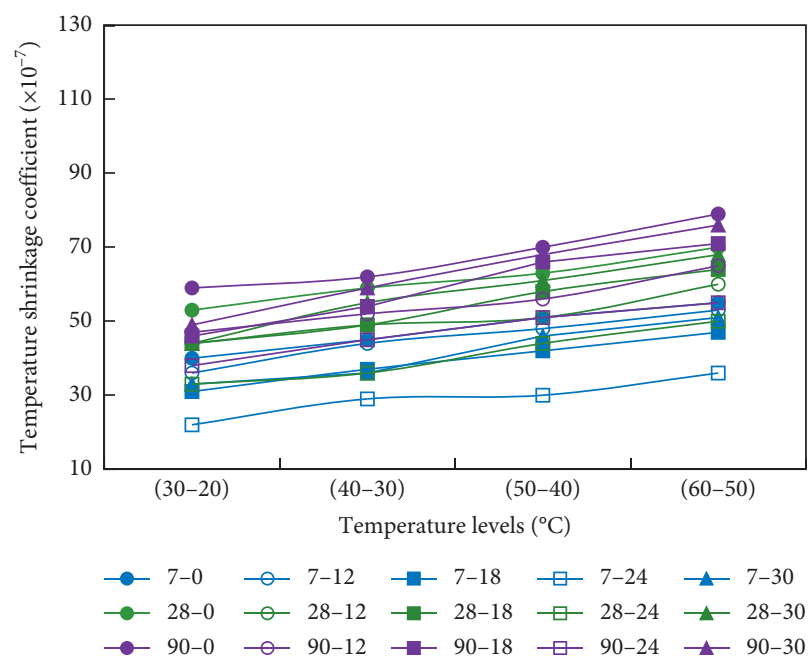

(b)

Figure 18: Continued. 


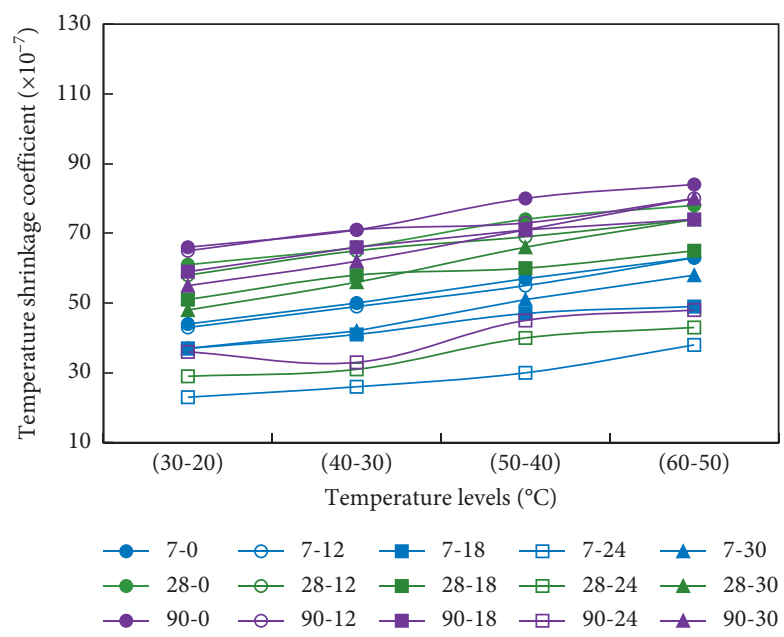

(c)

FIGURE 18: Trend chart of TSC of PFRC with different temperature levels: (a) cement content of 3.2\%, (b) cement content of 3.6\%, and (c) cement content of $4.0 \%$.

Compared with CSM without PVA, the TSCs of CSM with cement content of $3.2 \%, 3.6 \%$, and $4.0 \%$ averagely reduce by $15.2 \%, 18.2 \%$, and $19.4 \%$, respectively. Considering factors such as TSC, economy, and crack resistance effect comprehensively, the optimum cement content is $3.6 \%$.

3.8. Analysis of Crack Resistance Mechanism of PVA. A large number of experimental studies show that fiber can significantly enhance the crack resistance of concrete. The superposition method of stress intensity factor, $\mathrm{k}$ ( $\mathrm{k}$-superposition), based on the principle of linear elastic fracture mechanics, is widely applied in the fracture mechanism model of fiber-reinforced concrete $[45,46]$. Based on the theory of fracture mechanics and the displacement mode of crack surface, the crack propagation can be divided into three types: open type, shear type, and tear type (Figure 19). The drying shrinkage stress and temperature shrinkage stress of CSM base are easy to lead to open cracks, and the cracks are basically transverse cracks. Generally, their distribution also has a certain regularity [47].

Without considering creep and stress relaxation, shrinkage stress of PFRC is mainly composed of dry shrinkage stress and temperature shrinkage stress. When the shrinkage stress exceeds the ultimate tensile strength of the material, cracks will occur in the base:

$$
\sigma_{s}=E_{w} \alpha_{d}+E_{w} \alpha_{w}
$$

where $\sigma_{s}$ is shrinkage stress, $\mathrm{MPa} ; E_{w}$ is bending modulus; $\alpha_{d}$ is dry shrinkage coefficient; $\alpha_{w}$ is temperature shrinkage coefficient.

According to formula (1), the crack resistance index $K_{L}$ is calculated as follows:

$$
K_{L}=\frac{\sigma_{K}}{\sigma_{S}}=\frac{R_{c}}{E_{c} \times a_{d}+E_{c} \times a_{w}},
$$

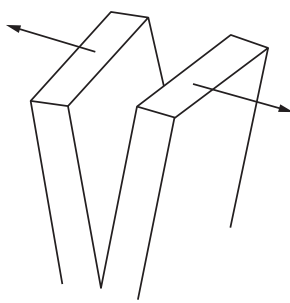

(a)

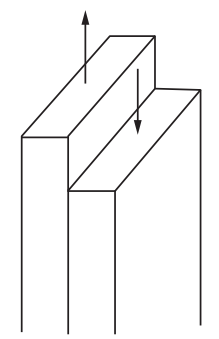

(b)

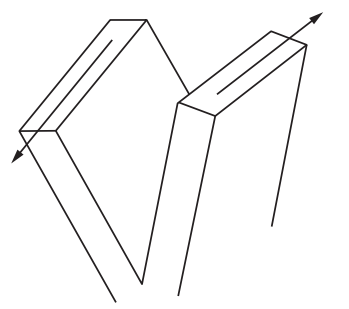

(c)

FIGURE 19: Crack propagation mode [42]: (a) open type, (b) shear type, and (c) tear type.

where $\sigma_{K}$ is antishrinkage stress, $\mathrm{MPa}$; $\sigma_{S}$ is shrinkage stress, $\mathrm{MPa} ; R_{c}$ is flexural tensile strength, $\mathrm{MPa} ; E_{c}$ is compressive resilience modulus, $\mathrm{MPa} ; a_{d}$ is dry shrinkage coefficient; $a_{w}$ is temperature shrinkage coefficient.

In this paper, the crack resistance index $K_{L}$ is proposed to characterize the crack resistance of PFRC. The larger $K_{L}$, the better the crack resistance.

The stress mode of CSM base is shown in Figure 20.

The crack resistance index $K_{L}$ of CSM with cement content of $3.6 \%$, fiber length of $24 \mathrm{~mm}$, fiber content of $0.9 \mathrm{~kg} / \mathrm{m}^{3}$, and fiber content of $0 \mathrm{~kg} / \mathrm{m}^{3}$ is shown in Table 6 . As shown in Table 6, compared with CSM without PVA, the crack resistance of PFRC with fiber content of $0.9 \mathrm{~kg} / \mathrm{m}^{3}$ improves by $44.4 \%$. 


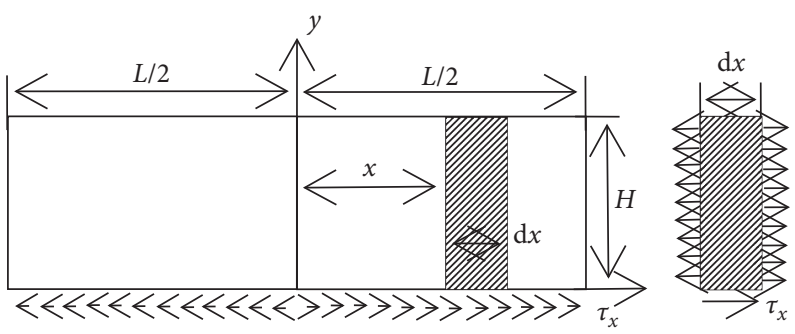

Figure 20: The stress mode of CSM base [44].

TABLE 6: Crack resistance index.

\begin{tabular}{lccccc}
\hline Fiber content $\left(\mathrm{kg} / \mathrm{m}^{3}\right)$ & FTS $(\mathrm{MPa})$ & CRM $(\mathrm{MPa})$ & DSC $\left(\times 10^{-6}\right)$ & TSC $\left(\times 10^{-7}\right)$ & Crack resistance index $K_{L}$ \\
\hline 0 & 1.34 & 2244 & 391 & 53 & 1.51 \\
0.9 & 1.42 & 2144 & 301 & 33 & 2.18 \\
\hline
\end{tabular}

\section{Conclusions}

On the basis of analyses of experimental results on crack resistance and mechanical properties of PFRC, the main findings and conclusions of this paper are summarized as follows:

(1) Fiber content, fiber length, cement content, and curing age are the main factors affecting the mechanical properties and crack resistance of CSM. The mechanical properties and crack resistance of CSM are obviously improved by adding PVA fiber. In terms of the improvement of the crack resistance of CSM, there are optimal values for cement content, fiber content, and fiber length, which separately are 3.6\%, $0.9 \mathrm{~kg} / \mathrm{m}^{3}$, and $24 \mathrm{~mm}$ under the test conditions.

(2) The incorporation of PVA fiber can effectively improve the anti-drying-shrinkage property and the temperature shrinkage property of CSM. When PVA fiber content is $0.9 \mathrm{~kg} / \mathrm{m}^{3}$, the optimum fiber length of PFRC is $24 \mathrm{~mm}$. With the increase of temperature levels, the TSC of PFRC nonlinearly increases.

(3) The crack resistance and toughening effect of PVA fiber are very remarkable. Taking crack resistance index as an evaluation index, compared with CSM without PVA fiber, the crack resistance of PFRC with fiber content of $0.9 \mathrm{~kg} / \mathrm{m}^{3}$ is improved by $44.4 \%$.

Adding fiber is one of the important means to improve the crack resistance of CSM base. However, the technical process and production cost of PFRC should be considered to further improve meeting the needs of practical application. In addition, the homogeneity of fiber distribution is one of the important factors affecting the road performance of CSM base. Using digital image processing technology to evaluate the homogeneity of fiber distribution is a forward-looking and intelligent technology with real-time, continuous, and quantitative characteristics, which is an important research direction.

\section{Data Availability}

The data supporting the findings of this study are included in the article.

\section{Conflicts of Interest}

The authors declare no conflicts of interest.

\section{Acknowledgments}

This work was supported by Anhui Transportation Holding Group Co., Ltd., the Science and Technology Research Program of Chongqing Municipal Education Commission (Grant no. KJQN201800704), and the Science and Technology Project of Department of Transportation of Hebei Province (QC2018-3), and Open Fund Project of Mountain Bridge and Materials Engineering Research Center of Ministry of Education of Chongqing Jiaotong University (QLGCZX-JJ2017-2).

\section{References}

[1] Y. Zheng, P. Zhang, Y. Cai, Z. Jin, and E. Moshtagh, "Cracking resistance and mechanical properties of basalt fibers reinforced cement-stabilized macadam," Composites Part B: Engineering, vol. 165, pp. 312-334, 2019.

[2] P. Zhang and Q. F. Li, "Experimental study on shrinkage properties of cement-stabilized macadam reinforced with polypropylene fiber," Engineering Mechanics, vol. 29, no. 12, pp. 1851-1860, 2010.

[3] M. Pasetto, "The re-utilisation of discarded building materials in cement-stabilised layers of road and airfield pavements," Waste Materials in Construction Wascon 2000-Proceedings of the International Conference on the Science and Engineering of Recycling for Environmental Protection, Harrogate, England 31 May, 1-2 June 2000, vol. 1, pp. 548-566, 2000.

[4] X. L. Yan, C. Y. Liang, and J. H. Xu, "Lastoplastic characteristics of cement-stabilized aggregate bases," China Journal of Highway and Transport, vol. 31, no. 1, pp. 29-36, 2019.

[5] M. L. Zeng, D. Luo, and C. F. Wu, "Anti-cracking properties of cement stabilized crushed stone pavement base materials of different aggregate structures," Journal of Hunan University (Natural Sciences), vol. 40, no. 10, pp. 1-7, 2013.

[6] Z. H. Sun, "Research on temperature shrinkage deformation properties of cement-stabilized macadam," Journal of Building Materials, vol. 12, no. 2, pp. 249-252, 2009.

[7] A. M. Sha, "Material characteristics of semi-rigid base," China Journal of Highway and Transport, vol. 21, no. 1, pp. 1-5, 2008. 
[8] L. J. Zhao, W. Z. Jiang, and J. R. Hou, "Influence of mixing methods on performance of compressive strength for cement stabilized macadam mixture," China Journal of Highway and Transport, vol. 31, no. 1, pp. 151-158, 2018.

[9] L. Q. Hu, Y. J. Jiang, and Z. D. Chen, "Road performance of cement stabilized aggregate of dense framework structure," Journal of Traffic and Transportation Engineering, vol. 1, no. 4, pp. 37-40, 2001.

[10] P. F. Wang, Z. Y. Guo, and C. J. Chen, "Research on cement stabilized macadam based on orthogonal method and anticracking performance," Journal of Building Materials, vol. 10, no. 5, pp. 616-621, 2007.

[11] X. G. X. Wang, "Relationship on index of physics and mechanics cement-stabilized aggregates between vibrating and static compacting methods," Journal of Harbin Institute of Technology, vol. 44, no. 10, pp. 70-74, 2012.

[12] H. H. Yang, P. W. Hao, and J. L. DaiI, "Road performance of cement-stabilized aggregate mixture with expansion agent," Journal of Traffic and Transportation Engineering, vol. 6, no. 1, pp. $48-51,2006$.

[13] F. M. Nejad, S. Asadi, S. Fallah, and M. Vadood, "Statisticalexperimental study of geosynthetics performance on reflection Cracking phenomenon," Geotextiles and Geomembranes, vol. 44, no. 2, pp. 178-187, 2016.

[14] J. S. Qian, X. R. Chen, and Y. Zheng, "MMLS3-Based research on anti-reflective cracking performance of geotextile," Journal of Tongji University (natural Science), vol. 46, no. 8, pp. 1042-1048, 2018.

[15] X. Z. Weng, "Study on anti-aging property of pavement modified polyester fiber reinforced concrete," Journal of Building Materials, vol. 13, no. 6, pp. 749-752, 2010.

[16] M. Mohamadi, M. Mohandesi, and M. Homayonifar, "Fatigue behavior of polypropylene fiber reinforced concrete under constant and variable amplitude loading," Journal of Composite Materials, vol. 47, no. 26, pp. 3331-3342, 2013.

[17] S.-J. Fan, "Mechanical and durability performance of polyacrylonitrile fiber reinforced concrete," Materials Research, vol. 18, no. 6, pp. 1298-1303, 2015.

[18] H. Zhang, J. Z. Xu, P. W. Hao et al., "Research on stability of hybridfiber asphalt mixture based on high temperature and continuous loading," Acta Materiae Compositae Sinica, vol. 34, no. 10, pp. 2344-2355, 2017.

[19] N.-H. Dinh, K.-K. Choi, and H.-S. Kim, "Mechanical properties and modeling of amorphous metallic fiber-reinforced concrete in compression," International Journal of Concrete Structures and Materials, vol. 10, no. 2, pp. 221-236, 2016.

[20] Q. F. Li, P. Zhang, and J. Shen, "Research on crack resistance of cement stabilized macadam reinforced with polypropylene fiber," Journal of Building Materials, vol. 11, no. 3, pp. 368374, 2008.

[21] Z. Liu, D. Wang, X. Wei, and L. Wang, "Impact of fiber diameter on-road performance of cement-stabilized macadam," The Baltic Journal of Road and Bridge Engineering, vol. 12, no. 1, pp. 12-20, 2017.

[22] Y. W. Wei, Y. N. Li, and N. X. Zheng, "Detection technology of mixing uniformity of PVA fiber cement stabilized macadam," Journal of Highway and Transportation Research and Development, vol. 36, no. 2, pp. 7-13+27, 2019.

[23] Y. W. Cao, C. Y. Wu, and T. T. Zheng, "PVA fiber dispersion evaluation method based on grey co-occurrence matrix theory," Journal of Harbin Institute of Technology, vol. 51, no. 1, pp. 157-161, 2019.

[24] N. Jain, A. Verma, and V. K. Singh, "Dynamic mechanical analysis and creep-recovery behaviour of polyvinyl alcohol based cross-linked biocomposite reinforced with basalt fiber," Materials Research Express, vol. 6, no. 10, Article ID 105373, 2019.

[25] B. Bolto, T. Tran, M. Hoang, and Z. Xie, "Crosslinked poly (vinyl alcohol) membranes," Progress in Polymer Science, vol. 34, no. 9, pp. 969-981, 2009.

[26] C. Zhang and M. L. Cao, "Mechanical property test of a multiscale fiber reinforced cementitious composites," Acta Materiae Compositae Sinica, vol. 31, no. 3, pp. 661-668, 2014.

[27] C. Victor, H. C. Wu, and Y. W. Chan, "Effect of plasma treatment of polyethylene fibers on interface and cementitious composite properties," Journal of the American Ceramic Society, vol. 79, no. 3, pp. 700-704, 1996.

[28] X. Ren and J. Li, "Multi-scale based fracture and damage analysis of steel fiber reinforced concrete," Engineering Failure Analysis, vol. 35, pp. 253-261, 2013.

[29] C. Li and M. Cao, "Fiber synergy in multi-scale fiber-reinforced cementitious composites," Journal of Reinforced Plastics and Composites, vol. 33, no. 9, pp. 862-874, 2014.

[30] JTG E30-2005, Test Methods of Cement and Concrete for Highway Engineering, People's Republic of China Industry Standards, Beijing, China, 2005.

[31] TG E42-2005, Test Methods of Aggregate for Highway Engineering, People's Republic of China Industry Standards, Beijing, China, 2005.

[32] JTG/T F20-2015, Technical Guidelines for Construction of Highway Roadbases, People's Republic of China Industry Standards, Beijing, China, 2015.

[33] JGJ/T-2010, Technical Specification for Application of Fiber Reinforced Concrete, People's Republic of China Industry Standards, Beijing, China, 2010.

[34] D. Wang, Y. Ju, H. Shen, and L. Xu, "Mechanical properties of high performance concrete reinforced with basalt fiber and polypropylene fiber," Construction and Building Materials, vol. 197, pp. 464-473, 2019.

[35] JTG E51-2009, Test Methods of Materials Stabilized with Inorganic Binders for Highway Engineering, People's Republic of China Industry Standards, Beijing, China, 2009.

[36] ASTM D2166/D2166M-16, Standard Test Method for Unconfined Compressive Strength of Cohesive Soil, ASTM International, West Conshohocken, PA, USA, 2013.

[37] J. Qin, J. Qian, Z. Li et al., "Mechanical properties of basalt fiber reinforced magnesium phosphate cement composites," Construction and Building Materials, vol. 188, pp. 946-955, 2018.

[38] P. A. Li, A. K. Desai, and J. A. Desai, "Evaluation of engineering properties forpolypropylene fibre reinforced concrete," International Journal of Advanced Engineering and Technology, vol. 3, no. 1, pp. 42-45, 2012.

[39] A. B. Kizilkanat, N. Kabay, V. Akyüncü, S. Chowdhury, and A. H. Akça, "Mechanical properties and fracture behavior of basalt and glass fiber reinforced concrete: an experimental study," Construction and Building Materials, vol. 100, pp. 218-224, 2015.

[40] M. Shafieifar, M. Farzad, and A. Azizinamini, "Experimental and numerical study on mechanical properties of ultra high performance concrete (UHPC)," Construction and Building Materials, vol. 156, pp. 402-411, 2017.

[41] J. Han, M. Zhao, J. Chen, and X. Lan, "Effects of steel fiber length and coarse aggregate maximum size on mechanical properties of steel fiber reinforced concrete," Construction and Building Materials, vol. 209, pp. 577-591, 2019.

[42] T. Simões, H. Costa, D. Dias-da-Costa, and E. Júlio, "Influence of fibres on the mechanical behaviour of fibre reinforced 
concrete matrixes," Construction and Building Materials, vol. 137, pp. 548-556, 2017.

[43] JTG D50-2017, Specfications for Design of Highway Asphalt Pavement, People's Republic of China Industry Standards, Beijing, China, 2009.

[44] P. Zhang, Q. F. Li, and H. Li, "Investigation of flexural properties of cement-stabilized macadam reinforced with polypropylene fiber," Journal of Materials in Civil Engineering, vol. 22, no. 12, pp. 1282-1287, 2010.

[45] J. P. Romualdi and J. A. Mandel, "Tensile strength of concrete affected by uniformly distributed and closely spaced short lengths of wire reinforcement," Journal of the American Concrete Institute, vol. 61, no. 6, pp. 27-37, 1964.

[46] J. C. Lenain and A. R. Bunsell, "The resistance to crack growth of asbestos cement," Journal of Materials Science, vol. 14, no. 2, pp. 321-332, 1979.

[47] L. Yuan, "Experimental study on cracking mechanism of semirigid base and its relationship with compaction quality," M.S. thesis, Chang'an University, Xi'an, China, 2017. 